\title{
Left atrial compression by a mediastinal bronchogenic cyst presenting with paroxysmal atrial fibrillation
}

\author{
ALBERTO VOLPI, AUGUSTO CAVALli, ALDO PIETRO MAGGIONI, \\ FRANCO PIERI-NERLI
}

From the Division of Cardiology, Ospedale G Fornaroli, Magenta-Milan, and the Division of Thoracic Surgery, Ospedale di Niguarda, Milan, Italy

Mediastinal bronchogenic cysts develop from abnormal budding of the primitive tracheobronchial tree. They are usually located in the mediastinum at the level of the tracheal bifurcation. In adults they are frequently asymptomatic and are discovered incidentally on the chest radiograph. As they enlarge they may cause symptoms referable to tracheal, bronchial, or oesophageal compression.' Extrinsic compression of the heart or great vessels appears to be a very rare occurrence. $^{23}$

\section{Case report}

A 36 year old man was admitted to the cardiac department because of the sudden onset of palpitation and dizziness. His previous clinical history was unremarkable. On admission the electrocardiogram showed atrial fibrillation with a rapid ventricular response of 170 beats/min and a pattern of incomplete right bundle branch block. The patient was

Address for reprint requests: Dr Alberto Volpi, Via Vetta d'Italia 3, 20144 Milano, Italy.

Accepted 8 June 1987 treated with intravenous digoxin and oral verapamil and theे atrial fibrillation gave way to sinus rhythm. The standard chest radiograph showed a widening of the tracheobronchia $\Phi$ angle, mimicking left atrial enlargement. Two dimensionas echocardiography disclosed a large echolucent cystic masscompressing the left atrium with a left atrial cavity mucks reduced in size (fig 1). The lateral radiograph and tomograms showed a homogeneous mediastinal mass. Computef tomography of the thorax showed a large, sharply defined mass located in the posterior and middle compartments 060 the mediastinum, compressing the left atrium (fig 2), the tracheobronchial angle and the oesophagus. At thoracotomg a cystic mass, measuring about $3 \times 4 \mathrm{~cm}$, was found jus beneath the bifurcation of the trachea extending from the oesophagus to the pericardium and compressing the lefo atrium. The entire cyst was easily dissected from the surrounding tissues and removed. The postoperative course was uneventful. The cyst had a smooth external surface an $\vec{\Phi}$ contained a brownish, thick material. Microscopic examina $\Xi$ tion showed the inner surface of the cyst to be lined with respiratory epithelium, beneath which was fibrous connective.

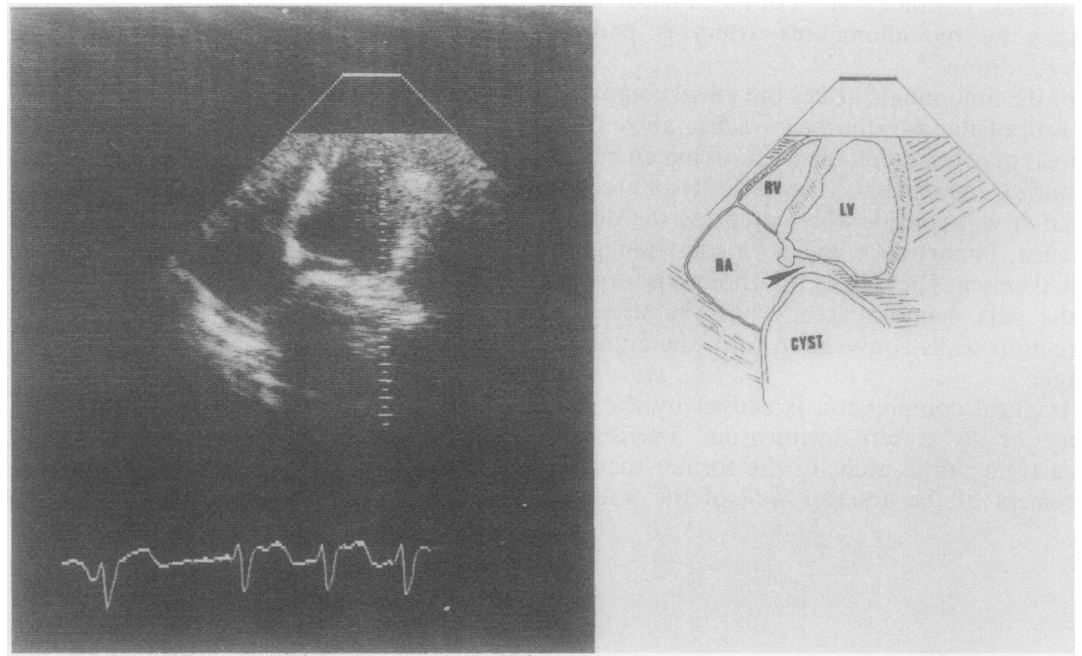

Fig 1 Graphic diagram (right panel) and two dimensional echocardiographic appearance (left panel) of the bronchogenic cyst on a four chamber apical view. The well demarcated cystic structure is seen compressing the left atrium (arrowhead), which is much reduced in size. 


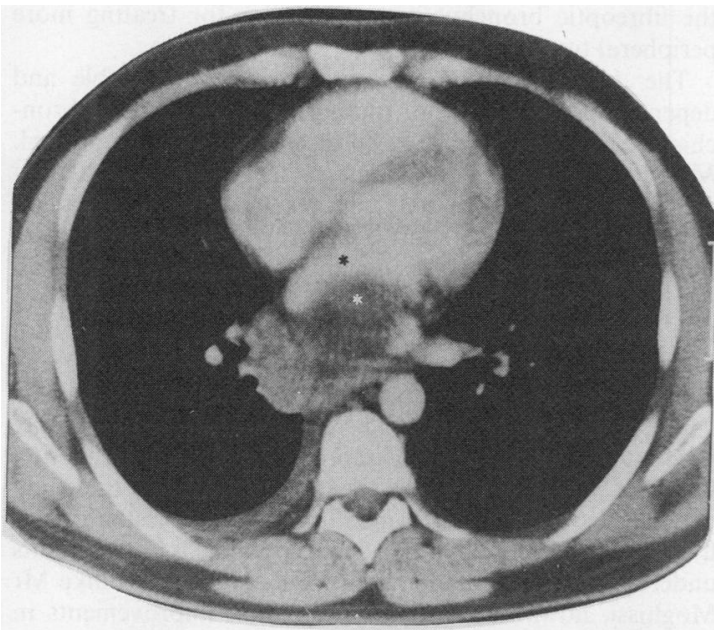

Fig 2 Computed tomography contrast enhanced scan of the thorax showing a mediastinal mass (white asterisk) posterior to and compressing the left atrium (black asterisk).

tissue. In some areas of the cyst wall the lining epithelium was absent and there was chronic inflammation.

\section{Discussion}

The occurrence of major complications from a bronchogenic cyst is uncommon and extrinsic compression of the heart appears to be quite exceptional. To the best of our knowledge this has been described in only two studies so far. Maier ${ }^{2}$ reported two cases of intrapericardial bronchogenic cyst in which sudden death was attributed to pressure on the heart or great vessels, and more recently a case of bronchogenic cyst compressing the pulmonary artery and right ventricular infundibulum has been described. ${ }^{3}$ Our case is the first to be reported of a bronchogenic cyst compressing the left atrium, a condition obviously having the potential for a catastrophic haemodynamic derangement. It is noteworthy that the first clue to the presence of the cyst was the sudden paroxysm of atrial fibrillation, probably due to mechanical stretching of the atrial myocardial fibres. Our report confirms the value of two dimensional echocardiography in the diagnosis of extracardiac space occupying lesions, ${ }^{4}$ and illustrates its role in differentiating between a solid and a cystic mass. ${ }^{5}$ We conclude that left atrial compression is a possible complication of mediastinal bronchogenic cyst and that two dimensional echocardiography is an extremely valuable diagnostic tool for its early detection.

We are indebted to Dr A Maggi and Dr P A Belloni for their valuable help with the patient.

\section{References}

1 Fraser RG, Paré JAP. Diagnosis of diseases of the chest. 2nd ed. Philadelphia: W B Saunders, 1977:614.

2 Maier HC. Bronchiogenic cysts of the mediastinum. Ann Surg 1948;127:476-502.

3 Harris M, Woo-Ming MO, Miller CG. Acquired pulmonary stenosis due to compression by a bronchiogenic cyst. Thorax 1973;28:394-8.
4 Chandraratna PAN, Littman BB, Serafini A, Whayne T, Robinson VH. Echocardiographic evaluation of extracardiac masses. Br Heart J 1978;40:741-9.

5 Pezzano A, Belloni A, Faletra F, Binaghi G, Colli A, Rovelli F. Value of two-dimensional echocardiography in the diagnosis of pericardial cysts. Eur Heart J 1983;4:238-46.

\section{Notices}

\section{Tuberculosis: the forgotten disease}

A grand round entitled "Tuberculosis: the Forgotten Disease" will be held at 5 pm on Tuesday 26 April 1988 in the Goldsmiths Theatre, London School of Hygiene and Tropical Medicine, London WC1E 7HT. It will consider how district health authorities should organise prevention and control programmes. The speakers are Dr K Citron, Dr RT Mayon-White, and Ms Shirley Goodwin. Admission free. Further information from Dr Martin McKee in the Department of Community Health (tel: 01-636 8636 ext 306).

\section{Courses on current advances in laboratory techniques}

Further details and application forms for the following courses are available from Professor Julia M Polak, Histochemistry Unit, Royal Postgraduate Medical School, Hammersmith Hospital, London W12 0HS. The fees are $£ 300$ (including lunch but not accommodation).

In vitro receptor autoradiographic technique, 16-20 May 1988: A course of lectures and practical demonstrations of this technique and how it is applied in analysis of the action of drugs, neurotransmitters and regulatory peptides. Topics include ligand and tissue preparation, autoradiography, quantification, localisation of binding sites at the ultrastructural level, and applications in pathology and research.

Modern immunocytochemistry, 10-14 October 1988: The theory and practice of immunocytochemical methods for light microscopy, including immunofluorescence, immunoenzyme, immunogold, and multiple labelling, with the use of direct, indirect, enzyme-antienzyme and avidin-biotin techniques. Students may work on their own projects. This course is suitable for anyone wishing to gain knowledge and practical experience in up to date immunocytochemistry.

Immunocytochemistry in cytopathology-methods and applications, 5-9 December 1988: Lectures and practical sessions on the preparation and immunostaining of whole cells in pathological specimens and cell cultures for light and electron microscopy. DNA hybridisation will be discussed, with slide review sessions. The course is suitable for pathologists, technicians, and scientists working with whole cells or cell cultures.

See also notices on $p 218$ 